\title{
Genotypic Variation in Prolonged Dormancy Symptoms in Apple Progenies
}

\author{
Iwan Labuschagné ${ }^{1}$, Bill Louw ${ }^{2}$, Karin Schmidt ${ }^{1}$, and Annalene Sadie ${ }^{3}$ \\ South African Agricultural Research Council, Fruit, Vine and Wine Research \\ Institute, Private Bag X5013, Stellenbosch, 7599, Western Cape, South Africa
}

Additional index words. Malus $\times$ domestica, chilling requirement, environmental adaptability

\begin{abstract}
The variability of characteristics associated with prolonged dormancy in apple (Malus $\times$ domestica Borkh.) progenies planted in the Western Cape region of South Africa was recorded over a three-year period. The time of initial vegetative and reproductive budbreak, the number of vegetative and reproductive budbreak, and the flowering duration were used as criteria. Data were collected on bearing trees of apple seedling families where the cultivars Anna and Golden Delicious were used as a common parent. Analysis of variance detected significant variation among seedling families for time of budbreak, number of breaking buds, and flowering duration in 'Golden Delicious' families. 'Braeburn' $x$ 'Golden Delicious' consistently produced seedlings with higher numbers of breaking buds and 'Golden Delicious' $x$ 'Prima' showed significantly lower numbers than other 'Golden Delicious' families. In 'Anna' families, significant differences were found for time of budbreak. 'Anna' families showed higher variability within families than 'Golden Delicious' families. Comparisons of progenies of 'Anna' and 'Golden Delicious' showed large differences in variation for the time of budbreak and for duration of flowering. Mean budbreak of 'Anna' progenies did not differ from 'Golden Delicious' progenies. Associations were found between initial time of budbreak and number of breaking buds as well as time and flowering duration. Results reveal high genetic variance in prolonged dormancy symptoms among seedlings within apple families which can be directly ascribed to high levels of heterozygosity in the cultivars used, and should be further explored for the purposes of breeding and selection.
\end{abstract}

Apple production areas of South Africa experience fluctuations in temperature during and between winters that harmfully affect the ultimate fruit set and fruit quality. The average winter chilling periods in two of the most important apple producing areas, Elgin (lat. $34^{\circ} \mathrm{S}$ ) and Bokkeveld (lat. $33^{\circ} \mathrm{S}$ ), are 850 and 1300 chill units (CU), respectively. Apple producers in these areas apply chemical agents to induce more uniform budbreak and thereby achieve better fruit set and fruit quality. Dinitrortho-cresol mineral oil (DNOC) is widely used, but is costly and because of environmental and health concerns, use of this chemical is to be phased out by 2005 . Hence, there is an urgent need to develop apple cultivars better adapted to these low chill conditions. This will reduce production costs by eliminating the need for application of DNOC and other dormancy-breaking chemicals and

Received for publication 18 Oct. 2000. Accepted for publication 21 May 2001. This study was funded by the South African Fruit Producers Trust. This paper is submitted by the senior author in partial fulfillment of the requirements for an academic degree in Genetics.

${ }^{1}$ To whom reprint requests should be addressed. Fax: + 272187 42006, E-mail: iwan@infruit.agric.za.

${ }^{2}$ Senior Lecturer in Genetics, Faculty of Agriculture, Dept. of Genetics, Stellenbosch Univ. Matieland, 7602, Western Cape, South Africa. ${ }^{3}$ Lecturer in Biometry, Faculty of Agriculture, Dept. of Genetics, Stellenbosch Univ., Matieland, 7602 , Western Cape, South Africa. may contribute to extending the overall production area for apples.

The complex nature of dormancy and related processes in temperate fruit trees has led to various quantitative and semi-quantitative measures of dormancy release and to a profusion of poorly defined terms, that are sometimes ambiguous. However, the following terminology has emerged as consistent and useful, and has been adopted in the present study. Control of dormancy by factors residing within the bud itself is referred to as endodormancy while control by factors in the plant but outside of the bud as paradormancy and control by environmental factors as ecodormancy (Khan, 1997; Lang, et al., 1985). Endodormancy includes the requirement for exposure to low temperatures before active shoot growth in the spring, generally referred to as the chilling requirement (Sorensen, 1983). The time of budbreak, as measured from an appropriate origin date, is related to endodormancy (Bradshaw and Stettler, 1995). The endodormant period ends when the chilling requirement has been met. The chilling requirement is a major determinant of time of budbreak. Abnormal growth characteristics observable under mild winter conditions, i.e., temperatures not low enough to meet the chilling requirement, have been variously referred to as symptoms of prolonged dormancy, delayed foliation or extended rest (Jacobs et al., 1981; Janick et al., 1996). Prolonged dormancy symptoms occur as a result of an unmet chilling requirement at temperatures in the range between 4 and $9{ }^{\circ} \mathrm{C}$ (Richardson et al., 1974) during the rest period, or as a result of unfavorable temperatures during the period of normal budbreak (Cook et al., 1998; Hauagge and Cummins, 1991a; Mauget and Rageau, 1988). Symptoms include reduced break of vegetative and reproductive buds, prolonged flowering duration, lower fruit set, and uneven fruit size. The most prominent symptom is the absence or extended delay of lateral vegetative budbreak. Prolonged dormancy symptoms are an indication of poor adaptation to mild winter climates (Martinez et al., 1999). These symptoms commonly occur in orchards in the Western Cape region of South Africa since the chilling requirement for normal dormancy release of most commercial cultivars is simply not met.

Most studies of chilling requirements have been based on clones of single cultivars and rootstocks (Cook et al., 1998; Mauget and Rageau, 1988; Powell, 1986) resulting in some understanding of the mechanism of dormancy. However, it appears that the genetic variation in chilling requirement of seedling families obtained by crossing different cultivars has not been thoroughly explored. We believe that the assessment of genetic variation in seedling families from crosses of parents from diverse genetic backgrounds will be an aid in understanding the basic factors controlling winter chilling requirement and dormancy release. Since apple breeding is a costly and long term process due to the long juvenile period of trees, results of such studies demonstrating genetic variability in families of seedlings should be useful to breeders in providing guidelines for the design of efficient breeding and selection programs.

The present study was undertaken to obtain estimates of the variances of characteristics related to prolonged dormancy in adult apple seedlings planted in mild winter conditions. The specific objectives were to: 1) quantify the variation within and between adult apple seedlings families for further exploration in a breeding program for improved climatic adaptation; and 2) develop evaluation criteria for winter chilling requirement and prolonged dormancy.

\section{Materials and Methods}

Plant material. Apple seedlings from controlled crosses were randomly selected from eight families planted in orchards for fruit quality breeding. The crosses had been made for the purpose of evaluation of fruit characteristics with no attention to any specific mating design. Four families with the high chilling 'Golden Delicious' as one parent and four with the low chilling 'Anna' as one parent were used. 'Anna' has one of the lowest chilling requirements found in Malus $\times$ domestica Borkh. (Brooks and Olmo, 1972), $\pm 300 \mathrm{CU}$, compared to $\pm 1500 \mathrm{CU}$ for 'Golden Delicious' (Hauagge and Cummins, 1991b). 'Golden Delicious' was used as a common female parent with 'Prima', 'Summerking', 'Starking Delicious', and 'Braeburn' as male 
parents. 'Anna' was used as a common male parent in crosses with 'Austin', 'Sharpe's Early', 'Kirks', and 'Summerred'. No records are available on chilling requirements of the other parents, other than for 'Braeburn' $( \pm 1100$ CU), 'Prima' ( $\pm 1100 \mathrm{CU})$, and 'Summerred' ( \pm 999 CU) (Hauagge and Cummins, 1991b; Hauagge, personal communication). Seedlings from each family were randomly selected and the same seedlings were used for measurements during the growing seasons of 1996 , 1997, and 1998. The aim was 60 seedlings from each family where possible, but numbers were ultimately between 50 and 60 . There was no selection performed at the seedling stage and there was no chance of inadvertent selection for a trait with possible linkage to chilling requirement before the trees were put into the field. The first set of data was recorded during 1996 in the seventh growing year of the 'Golden Delicious' families and the fifth growing year of the 'Anna' families.

Planting design. Seedlings were planted in an orchard in the Western Cape region of South Africa where inadequate winter chilling for standard apple cultivars is normally experienced. The original plantings were not planned to meet the specific aims of the present study. Sibling seedlings within families were planted adjacently in family rows and all four families with a common parent were growing together. However, the areas in which seedlings were planted were frequently inspected and appeared to be adequately uniform and free of any sources of serious bias which might influence the results. Subsequent measurements on clonally propagated selections of this material in properly designed trials provided some support for the assumption of negligible or no bias in the results. Genetic parameters have previously been estimated in trials of this nature in several fruit tree crops (Dicenta et al., 1993; Hansche et al., 1972; Tancred et al., 1995). The four 'Anna' families were planted $\approx 100 \mathrm{~m}$ from the 'Golden Delicious' families and here it seemed advisable to judge any differences between these major groups with caution. Orchard management was typical of standard commercial practice except that no pruning, chemical thinning, or rest-breaking treatments were performed.

Data collection and measurements. Preliminary observations identified three major criteria quantifying seedling reaction to winter chilling and prolonged dormancy under suboptimal climatic growing conditions: 1) the date of initial vegetative budbreak (IVB), scored as the time of the first sign of green leaves emerging from any vegetative bud; 2) the total number of breaking buds, both reproductive and vegetative; and 3) the flowering duration. Reproductive budbreak was scored as the number of reproductive buds that had burst at the date of last reproductive budbreak (LRB), i.e., the time when the last flower buds on the tree had reached the balloon stage. Vegetative budbreak was scored as the number of buds that had burst $21 \mathrm{~d}$ after the IVB, a period regarded as adequate for apple trees to express ability to overcome the state of dormancy (Faust et al., 1995; Hauagge and
Cummins, 1991b). The flowering duration was calculated as the difference between the date of initial reproductive budbreak (IRB), scored at the first sign of flowers in the tight cluster stage and LRB.

Three intact branches per seedling tree at even height and growing direction were randomly selected to record the number of buds and shoots on 3 years of growth. Normally, one-year-old shoots are used as analogous units to represent adult tree behavior (Cook et al., 1999; Costes and Guédon, 1997). In this study, branches with three season's growth were therefore regarded as suitable and representative. The total length of the 3year-old selected branches was recorded and the number of side shoots on these branches was recorded in the following classes: $0.5-5$ $\mathrm{cm}, 5-15 \mathrm{~cm}, 15-30 \mathrm{~cm}$ and shoots $>30 \mathrm{~cm}$. Budbreak was then expressed as the number of buds per $100 \mathrm{~cm}$ length of shoot. This measurement could be justified, whereas there was no association found between number of budbreak and total number of buds per $100 \mathrm{~cm}$ length of shoot or internode length (unpublished data). During the second and third year of data collection the number of vegetative budbreak was recorded at $21 \mathrm{~d}$ and $42 \mathrm{~d}$ after IVB in order to assess the increase of budbreak over time as an indication of the period of vegetative budbreak. Chill units were calculated according to a modified Utah model found to be more suitable for local chilling conditions where negative $\mathrm{CU}$ values are not carried from one day to the next (LinsleyNoakes et al., 1994).

Variance structure. The variance structure in the seedling families may be broken down as follows, where the primary interest lies in estimating the underlying causal components of variance from the observations, applying standard quantitative genetic principles (Falconer and Mackay, 1996):

(i) variance of seedling trees within families of the same cross

$$
\sigma_{w}^{2}=\sigma_{g}^{2}+\sigma_{e}^{2}
$$

where

$\sigma_{g}^{2}=$ a genetic component (generated by crossing in this case), and

$\sigma_{e}^{2}=$ a component ascribable to environmental variables within the trial orchard

(ii) variance between families

$$
\begin{aligned}
& \text { where } \sigma_{B}^{2}=\sigma_{G}^{2}+\sigma_{W}^{2} \\
& \sigma_{G}^{2}=\text { the genetic variance between } \\
& \text { families for a given common parent } \\
& \text { ('Golden Delicious' or 'Anna'). }
\end{aligned}
$$

If we had have had repeated measurements on clones of a given genotype (say clones of size $\mathrm{N}$ per seedling) in just one season, the analysis of variance (ANOVA) and expected mean squares (EMS) for the estimation of components would then read:
Between families ( $\mathrm{N}$ trees per family)

$$
\sigma_{e}^{2}+n \sigma_{g}^{2}+N n \sigma_{G}^{2}
$$

Between seedlings within families

$$
\sigma_{e}^{2}+n \sigma_{g}^{2}
$$

Within clones of one seedling

$$
\sigma_{e}^{2}
$$

The intraclass correlation coefficient relevant to selection between seedling within crosses is

$$
t=\frac{\sigma_{g}^{2}}{\sigma_{g}^{2}+\sigma_{e}^{2}} \quad \text { estimated by } \quad \frac{A-B}{A+(n-l) B}
$$

with standard error (SE) of the estimate

$$
\operatorname{SE}(t)=\sqrt{\frac{2[1+(n-1) t]^{2}(1-t)^{2}}{n(n-1)(N-1)}}
$$

The equivalent intraclass correlation coefficient relevant to selection between families is

$$
t=\frac{\sigma_{G}^{2}}{\sigma_{G}^{2}+\sigma_{W}^{2}}
$$

(used here for comparative purposes only).

In the present experiments, the repetition of measurement was in fact on the same tree in different seasons, involving possible genotype-environment interactions at two levels, viz.,

(i) year $\times$ family interaction, $\sigma_{G E}^{2}$ and

(ii) year $\times$ seedling interaction within families, $\quad \sigma_{g E}^{2}$

Conceptionally, ANOVA and EMS can then be done in two parts (Kempthorne, 1957), assuming $y$ years of measurement and $N$ trees per family:

(i) Years (Y) not relevant

Families (F)

$$
\sigma^{2}+N \sigma_{G E}^{2}+N y \sigma_{G}^{2}
$$

$\mathrm{Y} \times \mathrm{F}$ interaction

$\sigma^{2}+N \sigma_{G E}^{2}$

Residual

$$
\sigma^{2}
$$

(ii) Seedlings within

families

$\left(\sigma_{e}^{2}+N \sigma_{g E}^{2}\right)+y \sigma_{g}^{2}$

$\mathrm{Y} \times$ trees within families

$$
\left(\sigma_{e}^{2}+\sigma_{g E}^{2}\right)
$$

Note that in the latter analysis, the environmental variance (within orchard) and genotype $\times$ environment interaction cannot be estimated separately, since only one observation is made on each tree each year. Estimation of the intraclass correlation follows the same steps as above but the actual value is reduced if genotype $\times$ environment interaction is present. 
The ANOVA was carried out on measurements for separate groups ('Anna' and 'Golden Delicious' families). Separate analyses were carried out for each year, and a joint analysis over the three years to test for Year and Year $\times$ Family $(\mathrm{Y} \times \mathrm{F})$ interaction effects and to estimate variance components and intraclass correlations. The seedling-withinfamilies mean square was used to compare between families if $\mathrm{Y} \times \mathrm{F}$ interaction was nonsignificant, i.e. differences between family means were compared with differences between seedlings within families. In cases where significant $\mathrm{Y} \times \mathrm{F}$ interaction was found, the mean square for $\mathrm{Y} \times \mathrm{F}$ was used as error term in the ANOVA. The analyses were performed using SAS general linear model procedures (SAS Institute, Cary, N.C.) after testing for heterogeneity of variance by means of the Levene test (Snedecor and Cochran, 1991) and the Shapiro-Wilk test for normality (Shapiro and Wilk, 1965). Data sets were weighted for homogeneity of variance and transformed to achieve normal distributions if the tests showed skewed distributions. Multiple comparisons were performed using Student's $t$ LSD test. Variance components and intraclass correlation coefficients were calculated using the SAS Variance Component Estimation procedure.

\section{Results}

Winter chilling conditions recorded up to the end of August for the 3 years of observation were 621 CU for 1996, 676 CU for 1997 , and $748 \mathrm{CU}$ for 1998 . Unusually cold temperatures for this area were experienced during the first year (1996) when the total CU accumulation toward the end of November was 921 .

Between-family variation. ANOVA detected significant levels of variation for IVB among 'Anna' families (Table 1), and significant variation among 'Golden Delicious' families for IVB and number of budbreak (Table 1). Family means over three years of measurement are shown in Fig. 1. 'Anna' $x$ 'Austin' was consistently earlier than the other families. The 'Golden Delicious' x 'Braeburn' family showed budbreak earlier than the other 'Golden Delicious' families and had a higher number of budbreak. 'Golden Delicious' $x$ 'Prima' showed a lower number of budbreak. In 'Golden Delicious' families the variance for IVB, expressed as a percentage of the total variance was $19.6 \%$ compared to $4.8 \%$ for 'Anna' families (Table 2). Corresponding values for the number of budbreak were $8.7 \%$ and $0.5 \%$ respectively. Differences among families for flowering duration were not significant for either set (Table 1) and intraclass correlation coefficients (Table 2) also indicate relatively low between family variation in this variable.

Year $\times$ Family interaction. Significant $\mathrm{Y} \times \mathrm{F}$ interaction is apparent for 'Golden Delicious' crosses for all measurements, but only for flowering duration in 'Anna' crosses (Table 1). Expressed as a percentage of the total variance (Table 2 ), $\mathrm{Y} \times \mathrm{F}$ interaction was
Table 1. ANOVA for three criteria associated with prolonged dormancy symptoms in 'Anna' and 'Golden Delicious' families. Data were recorded on adult trees in suboptimal winter chilling conditions during three years $(1996,1997$, and 1998).

\begin{tabular}{|c|c|c|c|c|c|c|c|c|}
\hline \multirow{2}{*}{$\begin{array}{l}\text { Criteria and } \\
\text { source of variation }\end{array}$} & \multicolumn{4}{|c|}{ Anna Families } & \multicolumn{4}{|c|}{ Golden Delicious Families } \\
\hline & $d f$ & $M S$ & $F$ & $P$ & $d f$ & $M S$ & $F$ & $P$ \\
\hline \multicolumn{9}{|l|}{ Time of budbreak } \\
\hline Year & 2 & 9.559 & 9.76 & 0.0001 & 2 & 68.272 & 24.84 & 0.0001 \\
\hline Family & 3 & 11.029 & 11.26 & 0.0001 & 3 & 76.689 & 27.91 & 0.0001 \\
\hline $\mathrm{Y} \times \mathrm{F}$ interaction & 6 & 271.590 & 0.08 & 0.9978 & 6 & 2.748 & 2.75 & 0.0120 \\
\hline Residual & 699 & 0.979 & & & 686 & 1.000 & & \\
\hline \multicolumn{9}{|c|}{ Total number of budbreak } \\
\hline Year & 2 & 12.227 & 12.23 & 0.0001 & 2 & 183.087 & 65.39 & 0.0001 \\
\hline Family & 3 & 2.605 & 2.60 & 0.0509 & 3 & 33.165 & 11.84 & 0.0062 \\
\hline $\mathrm{Y} \times \mathrm{F}$ interaction & 6 & 0.741 & 0.74 & 0.6166 & 6 & 2.800 & 2.80 & 0.0107 \\
\hline Residual & 699 & 1.000 & & & 688 & 1.000 & & \\
\hline \multicolumn{9}{|l|}{ Flowering duration } \\
\hline Year & 3 & 198.070 & 21.45 & 0.0018 & 2 & 101.150 & 22.82 & 0.0016 \\
\hline Family & 3 & 9.096 & 0.99 & 0.4603 & 3 & 10.723 & 2.42 & 0.1645 \\
\hline $\mathrm{Y} \times \mathrm{F}$ interaction & 6 & 9.233 & 4.50 & 0.0002 & 6 & 4.433 & 4.15 & 0.0004 \\
\hline Residual & 672 & 2.051 & & & 642 & 1.069 & & \\
\hline
\end{tabular}

small compared to other components contributing to the total variance.

Within family variation. Significant variation between seedlings for all traits measured reflects that the genotypic variation present within families was much higher than that between families (Table 2). A high degree of variation was present within 'Anna' families for IVB and for flowering duration as is evident from values and variances in Table 3 and Fig. 2. The variance component between seedlings for IVB was $84 \%$ and $38 \%$ of the total variance for 'Anna' and 'Golden Delicious' crosses, respectively (Table 2). Corresponding values for the number of breaking buds were $43 \%$ for 'Anna' and $24 \%$ for 'Golden

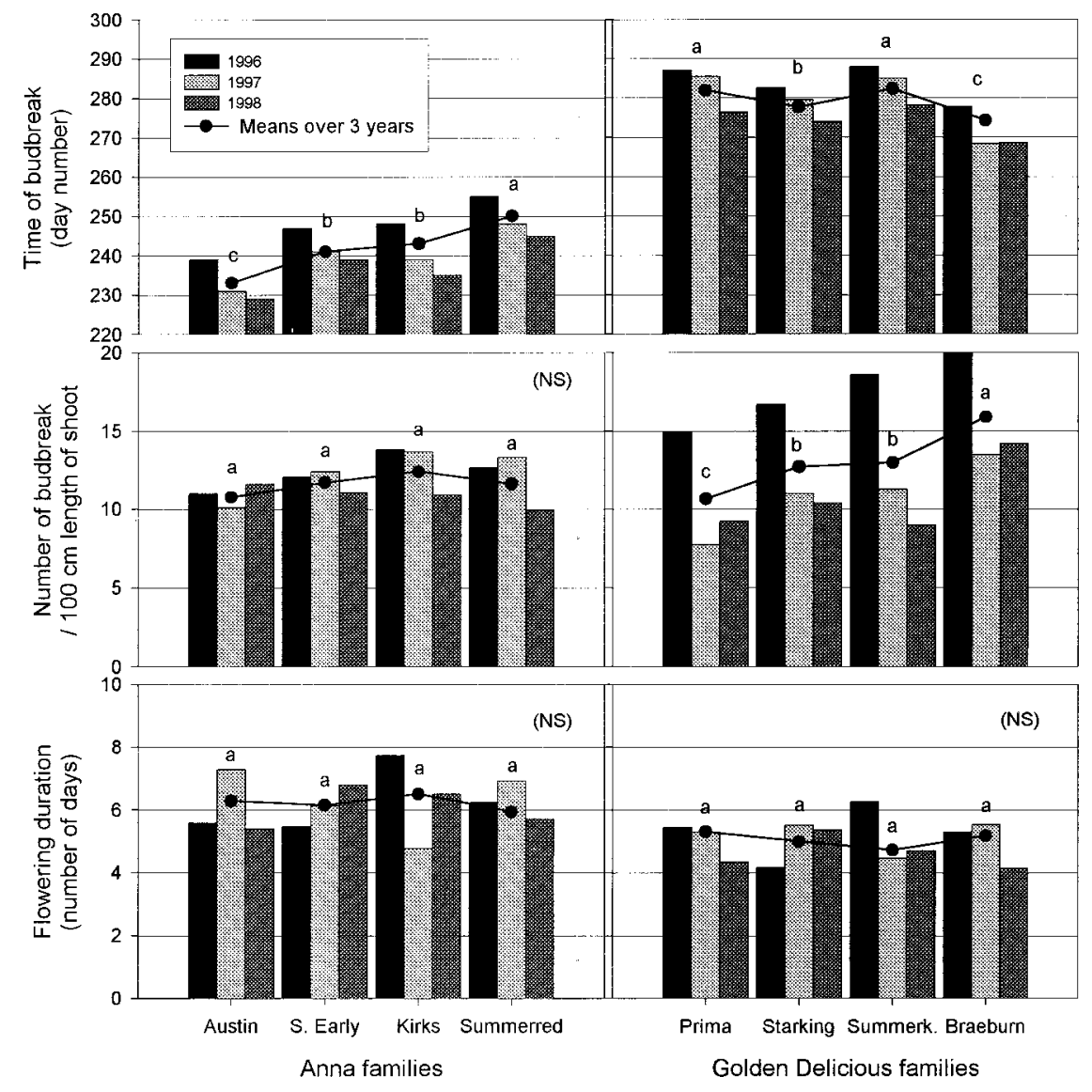

Fig. 1. Between-family variation for mean time and total number of breaking buds and for mean flowering duration over three years in 'Anna' and 'Golden Delicious' progenies. Families include 'Anna' as a common parent with 'Austin', 'Sharpe's Early', 'Kirks', and 'Summerred'; and 'Golden Delicious' as a common parent with 'Prima', 'Starking Delicious', 'Summerking' and 'Braeburn'. ANOVA was performed separately for 'Anna' and 'Golden Delicious' progenies. Student's $t$ LSD test was used to separate means. Letters indicate significant differences between means at $P \leq 0.05$. (Values for flowering duration were $\log$ transformed before analysis). 
Table 2. Variance components and intra-class correlation coefficients for criteria associated with prolonged dormancy symptoms in four 'Anna' and four 'Golden Delicious' families.

\begin{tabular}{|c|c|c|c|c|c|c|c|c|}
\hline \multirow[b]{2}{*}{ Criteria } & \multicolumn{5}{|c|}{ Source of variation } & \multirow[b]{2}{*}{ Residual } & \multicolumn{2}{|c|}{ Intraclass correlation } \\
\hline & Families & Year (Y) & Family (F) & $\mathrm{Y} \times \mathrm{F}$ & Within F & & $t_{1}{ }^{2}$ & $t_{2}^{\mathrm{y}}$ \\
\hline (IVB) & Golden Delicious & 21.06 & 26.99 & $4.15( \pm 2.85)$ & $53.04( \pm 6.08)$ & 32.79 & 0.20 & $0.62( \pm 0.19)$ \\
\hline budbreak & Golden Delicious & 15.09 & 3.89 & $0.91( \pm 1.23)$ & $10.81( \pm 1.40)$ & 14.12 & 0.09 & $0.34( \pm 0.21)$ \\
\hline Flowering & Anna & 0.83 & 0.01 & $0.14( \pm 0.09)$ & $0.67( \pm 0.12)$ & 1.39 & 0.00 & $0.32( \pm 0.19)$ \\
\hline duration & Golden Delicious & 0.44 & 0.04 & $0.07( \pm 0.05)$ & $0.17( \pm 0.05)$ & 0.90 & 0.02 & $0.12( \pm 0.10)$ \\
\hline
\end{tabular}

${ }^{\mathrm{Z}}$ Intraclass correlation coefficient for between-family variation: $t_{1}=\sigma_{G}^{2} / \sigma_{G}^{2}+\sigma_{V}^{2}$

Intraclass correlation coefficient for within-family variation: $t_{2}=\sigma_{g}^{2} / \sigma_{g}^{2}+\sigma_{e}^{2}$.

$\mathrm{SE}(t)=\sqrt{\frac{2[1+(n-1) t]^{2}(1-t)^{2}}{n(n-1)(N-l)}}$

Delicious' crosses. Relatively high intraclass correlation coefficients within crosses are evident for IVB (0.92 for 'Anna' and 0.62 for 'Golden Delicious') compared to intraclass coefficients for number of breaking buds $(0.45$ for 'Anna' and 0.34 for 'Golden Delicious') (Table 2). Intraclass correlations for flowering duration were lower in both cases $(0.32$ for 'Anna' and 0.12 for 'Golden Delicious'). A low number of breaking buds ( $<10$ buds per $100-\mathrm{cm}$ length of shoot) was found in many 'Anna' and 'Golden Delicious' seedlings ( $40.7 \%$ and $23.9 \%$, respectively) (Fig. 2B). In general, 'Anna' families showed greater variation than 'Golden Delicious' families for all traits.

Variability between the 'Anna' and 'Golden Delicious' progenies. As stated earlier, the original plantings were not specifically planned to compare 'Golden Delicious' and 'Anna' progenies and any such comparison should therefore be made with care. However, some marked differences unlikely to be attributable to within season environmental factors at the experimental site became apparent and should perhaps not be ignored in future testing and selection decisions. These are illustrated in Fig. 2 and may be summarized as follows.

Seedlings of 'Anna' differed markedly from those of 'Golden Delicious' in the mean and distribution of IVB (Fig. 2A) showing initial budbreak at $\approx 180 \mathrm{~d}$ compared to $250 \mathrm{~d}$ in 'Golden Delicious'. For each year 65\%, $55 \%$, and $60 \%$ respectively, of 'Anna' seedlings exhibited budbreak earlier than the earliest seedlings of 'Golden Delicious'. A much wider time range from first to last budbreak was also apparent in the seedlings of 'Anna' (93 d), compared to the 'Golden Delicious' seedlings (36 d). This is also evident from the coefficients of variation: $11.7 \%$ in 'Anna' crosses and $3.1 \%$ in 'Golden Delicious'.

Although more seedlings in 'Anna' crosses appear in the lower distribution classes for total number of budbreak (Fig. 2B), the mean numbers do not appear to differ significantly. 'Golden Delicious' seedlings exhibited higher budbreak (17.48) in the first season compared to 12.32 for 'Anna' seedlings (Fig. 1) and the percentage of seedlings with budbreak numbers in excess of 15 per $100-\mathrm{cm}$ shoot length over all three seasons was $28 \%$ as against $31 \%$ in 'Golden Delicious' based on the data sum-
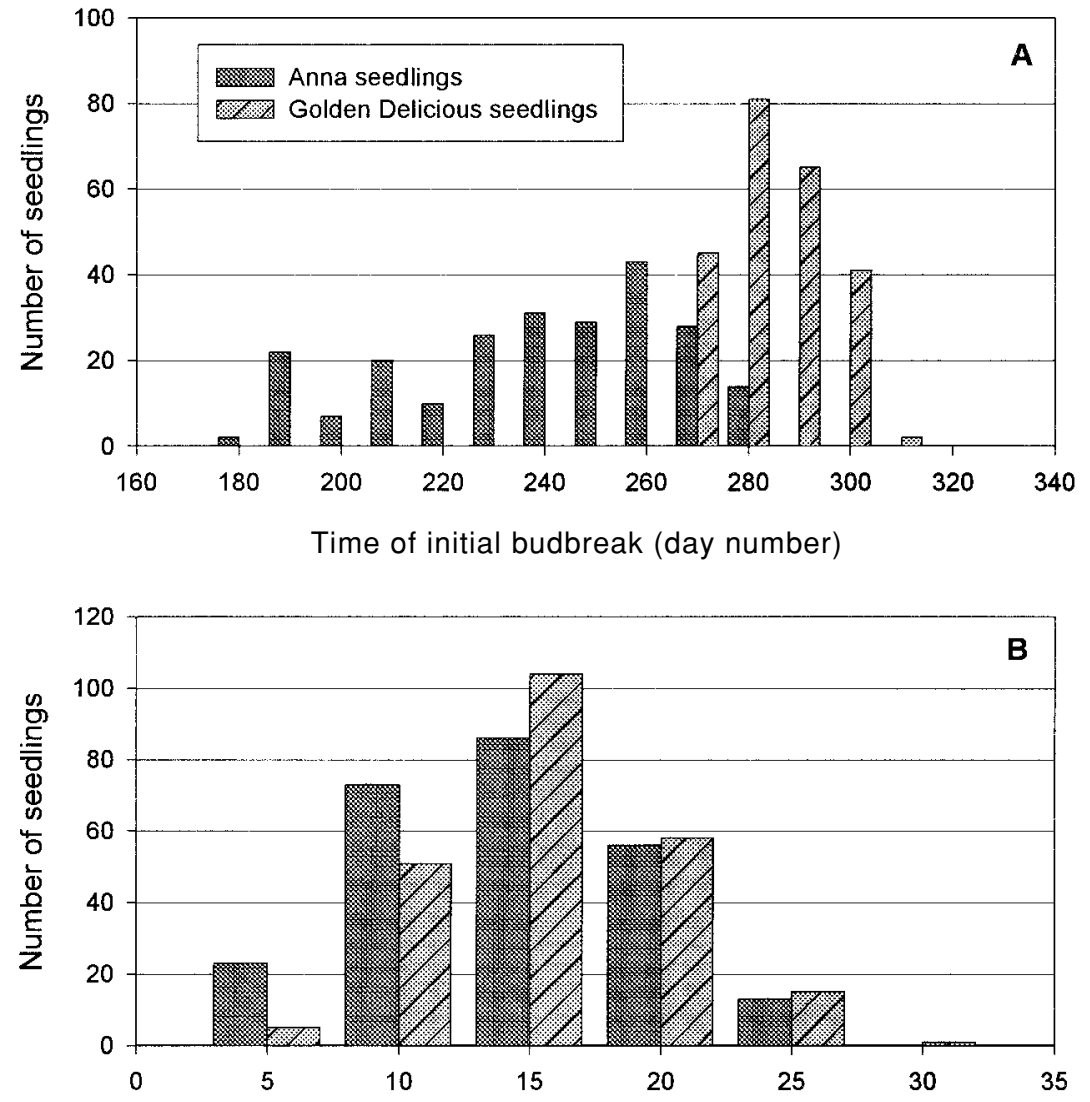

Number of breaking buds/100-cm length of shoot

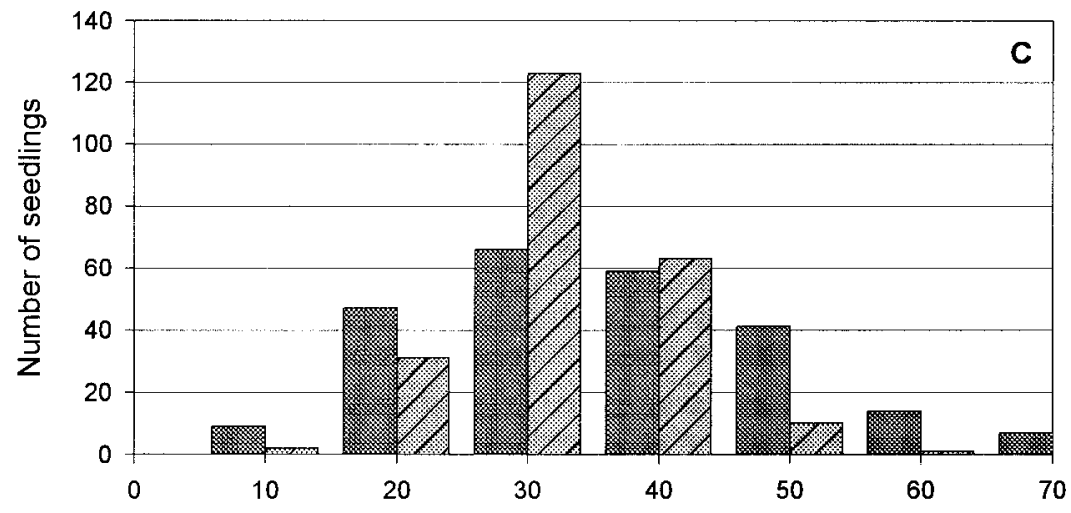

Flowering duration (number of days)

Fig. 2. Seedling frequency distribution of means over three years for (A) time of initial budbreak, (B) total number of budbreak and (C) flowering duration in eight apple families. 
marized in Fig. 2B. 'Anna' seedlings exhibited a wider range in flowering duration by some $13 \mathrm{~d}$ (Fig. 2C).

Year to year performance. The ANOVA indicates significant differences between years in all measurements in both family groups and might have been predicted from the different weather patterns recorded during these years in the region. However, yearly fluctuations in 'Golden Delicious' families were considerably higher than in 'Anna' families. Variance component analysis showed $15 \%$ attributable to year effects for IVB and $34 \%$ for number of budbreak in 'Golden Delicious' compared to $3.4 \%$ and $3.6 \%$ respectively in 'Anna' (Table 2). Yearly fluctuations for flowering duration were greater, being $\approx 27 \%$ for both family groups.

Correlation analyses. A positive association between IVB and number of budbreak was found in 'Anna' families, but in 'Golden Delicious' families the association was negative (Table 4). As indicated, more than half of the 'Anna' seedlings sprouted earlier than seedlings from 'Golden Delicious'. Of these, $39 \%$ showed low numbers of budbreak $(<10$ buds per $100 \mathrm{~cm}$ length of shoot) (Fig. 3A). During the second and third years, budbreak in 'Golden Delicious' seedlings occurred after final winter chilling accumulation and therefore no correlation analysis could be performed between data collected on CU accumulation and data on number of budbreak and flowering period.

Low correlations between the number of budbreak $21 \mathrm{~d}$ after IVB and the difference between number of buds sprouted 42 and 21 $\mathrm{d}$ after IVB were found in both years for both 'Anna' crosses $(r=-0.385$ and $r=-0.175$, respectively) and 'Golden Delicious' crosses ( $r=0.113$ and $r=-0.168$, respectively), implying little or no budbreak after $21 \mathrm{~d}$. Although the overall correlation coefficients was low, more seedlings in 'Anna' families with early budbreak showed a prolonged period of vegetative budbreak when compared with 'Golden Delicious' families (Fig. 3B). Higher correlations for IVB and flowering duration and for CU accumulation and flowering duration were found in 'Anna' families than in 'Golden Delicious' families (Table 4 and Fig. 3C).

\section{Discussion}

Low winter chilling and fluctuations in temperature with exceptionally hot days and extended cold accumulation towards the end of winter and spring were prevalent during this investigation. Prolonged dormancy is common under these climatic conditions. A substantial number of seedlings exhibited symptoms that included bare shoots without budbreak, delay of vegetative and reproductive budbreak and prolonged flowering periods. These symptoms were observed in seedlings of the high chill parent, 'Golden Delicious', and also in seedlings of the lowchill 'Anna'. Some seedlings of 'Anna' showed lower numbers of budbreak than seedlings of 'Golden Delicious'.
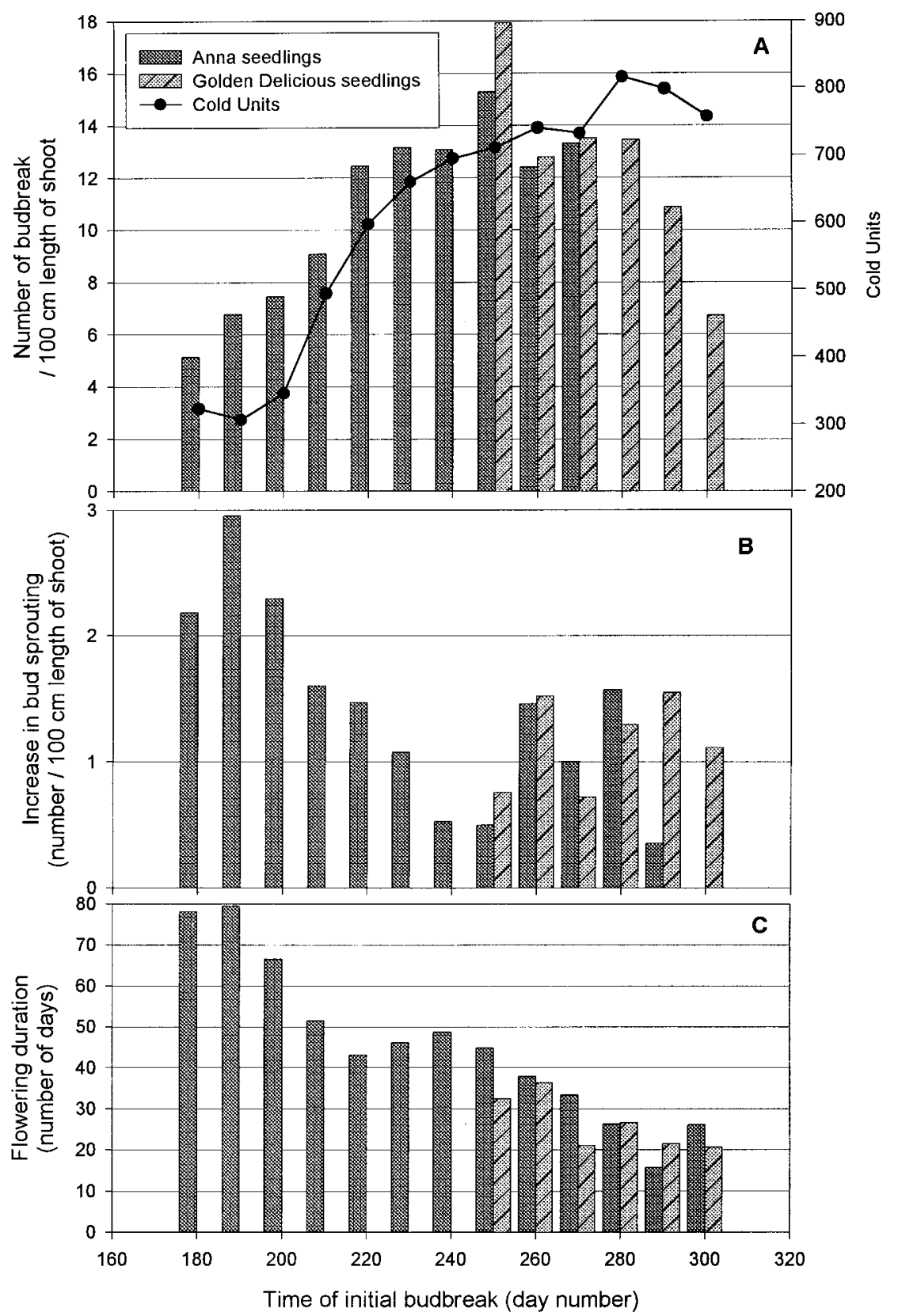

Fig. 3. Distribution curves for (A) mean number of budbreak over three years according to time of budbreak (IVB) and accumulation of cold units (B) for increased vegetative budbreak $21 \mathrm{~d}$ to $42 \mathrm{~d}$ after IVB and (C) mean flowering duration over three years in eight apple progenies.

Measurable variation between and within apple seedlings for characteristics associated with prolonged dormancy was found in all families and was generally higher for 'Anna'. 'Anna' X 'Austin' within the 'Anna' families and 'Braeburn' $x$ 'Golden Delicious' within the 'Golden Delicious' families, gave many seedlings with early budbreak. The chilling requirements of 'Braeburn' and 'Prima' were estimated to be similar, (1100 CU) when the percentage of terminal budbreak was used as a rating criterion on excised shoots (Hauagge, personal communication). In the present study, the 'Braeburn' $x$ 'Golden Delicious' cross showed a higher mean number of budbreak and the 'Golden Delicious' $x$ 'Prima' cross showed a significantly lower mean number of budbreak compared to the other 'Golden De- licious' families. Quantification of the genetic variance in these families will provide a better basis for future choices of parents with regard to these traits.

Within-family seedling variance was generally higher than that for between families for all measurements. It is common knowledge that apple cultivars are highly heterozygous and this is reflected in the variation in seedling families. (Brown, 1960). Variation for time of budbreak within 'Anna' families was more than 10-fold higher than for 'Golden Delicious' families. Variation in flowering duration and the period of vegetative budbreak was also higher in 'Anna' than in 'Golden Delicious' families. High numbers of seedlings in the middle classes suggest additive gene action, as has been reported previously for other 
Breeding, Cultivars, Rootstocks, \& Germplasm Resources

Table 3. Within-family variation for initial time of budbreak, number of budbreak and flowering duration. Values are averaged over three years.

\begin{tabular}{|c|c|c|c|c|c|c|c|c|c|c|c|c|}
\hline \multirow[b]{2}{*}{ Family } & \multicolumn{4}{|c|}{ Time of budbreak } & \multicolumn{4}{|c|}{ Total number of budbreak } & \multicolumn{4}{|c|}{ Flowering duration } \\
\hline & Min & Max & Mean & $\mathrm{SD}$ & Min & $\operatorname{Max}$ & Mean & SD & Min & $\operatorname{Max}$ & Mean & SD \\
\hline Anna X Sharpe's Early & 196 & 288 & 242.82 & 29.56 & 3.03 & 24.65 & 11.68 & 4.53 & 13.00 & 78.60 & 39.71 & 14.76 \\
\hline Anna $x$ Summerred & 203 & 285 & 250.00 & 26.17 & 4.27 & 23.99 & 11.59 & 4.10 & 47.50 & 66.00 & 37.36 & 11.83 \\
\hline $\mathrm{LSD}_{005}$ & & & 12.26 & & & & 7.07 & & & & 1.88 & \\
\hline G.D. ${ }^{z} \times$ Prima & 267 & 304 & 282.98 & 8.89 & 2.59 & 20.79 & 10.63 & 3.52 & 8.00 & 57.30 & 29.41 & 8.31 \\
\hline G.D. $\times$ Starking & 263 & 298 & 278.66 & 8.04 & 4.32 & 25.34 & 12.67 & 4.16 & 9.50 & 43.30 & 25.54 & 6.78 \\
\hline $\mathrm{LSD}_{005}$ & & & 9.16 & & & & 6.01 & & & & & 1.52 \\
\hline
\end{tabular}

${ }^{\mathrm{Z}} \mathrm{G} . \mathrm{D} .=$ 'Golden Delicious'.

Table 4. Correlation analyses for number of budbreak and flowering duration with time of budbreak and chill units accumulated in 'Anna' and 'Golden Delicious' families over a period of three years.

\begin{tabular}{|c|c|c|c|c|c|}
\hline \multirow[b]{2}{*}{ Criteria } & \multirow[b]{2}{*}{ Year } & \multicolumn{2}{|c|}{ Time of budbreak } & \multicolumn{2}{|c|}{ Chill units } \\
\hline & & Anna & G.D. ${ }^{z}$ & Anna & G.D. \\
\hline \multirow[t]{3}{*}{ Total number of budbreak } & 1996 & 0.66 & -0.31 & 0.67 & -0.29 \\
\hline & 1997 & 0.32 & -0.63 & 0.39 & $--y^{y}$ \\
\hline & 1998 & 0.12 & -0.36 & 0.23 & --- \\
\hline \multirow[t]{3}{*}{ Flowering duration } & 1996 & -0.33 & -0.39 & -0.33 & -0.40 \\
\hline & 1997 & -0.66 & -0.22 & -0.59 & --- \\
\hline & 1998 & -0.54 & -0.23 & -0.48 & --- \\
\hline
\end{tabular}

${ }^{\mathrm{z} G . D .}=$ 'Golden Delicious'.

${ }^{y}$ Budbreak occurred after total $\mathrm{CU}$ accumulation, therefore, no correlation analysis was possible for data on chill units, number of budbreak and flowering duration on 'Golden Delicious' families.

All values were significant at $P=0.001$, except for total number of budbreak and time of budbreak of 'Anna' families in $1998(P=0.07)$, N values about equal $(\mathrm{N}=216-236)$.

fruit tree traits (Bell and Janick, 1990; Hansche et al., 1966 and 1972). However, dominance for the length of dormancy period in 'Anna' crosses has also been reported (Hauagge and Cummins, 1991c).

Yearly climatic differences are known to contribute to the variability of several traits in fruit crops (Hansche et al., 1966, 1972; Tancred et al., 1995). We assessed consistency in family performance by estimating Year and Year $\times$ Family interaction variance components. Yearly differences contributed more to total variation than between family differences. High yearly fluctuations in family means for time and number of budbreak was found, particularly in 'Golden Delicious' seedlings. During the first season, the 'Golden Delicious' families showed a higher mean number of budbreak than 'Anna' families and this might be attributable to the higher $\mathrm{CU}$ accumulation. This may reflect greater responsiveness of 'Golden Delicious' seedlings to seasonal changes, as was also found in the variance components for year effects. Year to year variation in flowering duration was relatively large and can probably be explained by alternate bearing.

Year $\times$ Family interaction for all criteria was low as a percentage of total variation. The interaction that occurred suggests consistent or small variation in crossover performance of individual families from year to year. Year $\times$ Family interaction occurring in 'Golden Delicious' crosses for time and number of budbreak appeared not to be of the cross-over type interaction, implying that a family superior in one year performed well in other years as well.
However, Year $\times$ Family interactions for flowering duration do appear to be of a cross-over type, implying that a family may have superior flowering relative to others during one particular season. This may also be an explanation for lower between-family differences for flowering duration than for other traits. Certain cultivars are more prone to bear heavy crops in alternative years, and this tendency can be transmitted to their seedlings.

Absence of significant Year $\times$ Family interaction for number of budbreak in the 'Anna' families, suggests that a single year of testing might be adequate for selection and would imply much saving in cost and time. On the other hand, significant interaction as found in 'Golden Delicious' families point to a program of multi-year testing and selection based on mean performance averaged over years. The alternative strategy often suggested in breeding annual crops is to judiciously select a range of test locations likely to simulate the range of climatic and other environmental factors that normally occur from year to year.

Correlation between time and number of budbreak and flowering duration indicate that selection for early budbreak will not automatically select seedlings without prolonged dormancy symptoms and conversely that early budbreak is probably not useful for selecting for local conditions. Time of budbreak reflects chilling requirement under favorable climatic conditions (Hauagge and Cummins, 1991a; Weinberger, 1944), but early budbreak under unfavorable, fluctuating temperatures seemed to result in abnormal behavior.
Budbreak in seedlings of 'Golden Delicious' was later during a period of constant and higher temperatures, i.e., conditions that are more suitable for dormancy release. Absence of sufficient winter chilling seemed to result in prolonged dormancy symptoms in these seedlings. Distribution of seedlings according to time and number of budbreak identifies between day 230 (mid-August) and day 290 (mid October) as optimal (Fig. 3), and these points can be viewed as truncation points for the selection of adapted seedlings in local low-chill conditions.

Prediction of the timing of various events using phenological models, e.g., budbreak at specified intervals on excised 1-year-old shoots under forced conditions, is frequently used in horticultural studies. These models have been used in the investigation of chilling requirements of cultivars and in studies of dormancy release (Cook and Jacobs, 2000; Linsley-Noakes et al., 1994; Shaltout and Unrath, 1983; Wilson et al., 1975). The percentage of shoots with budbreak after a specified time, or the time of budbreak after a specified percentage of sprouting has occurred, have been used as criteria in these investigations. This approach for pre-screening and breeding purposes would seem not to be of much use, since no replication is possible when working with the very large numbers of young seedlings that would be necessary in the type of breeding program we propose. The occurrence of prolonged dormancy symptoms in seedlings where early budbreak occurred underlines the complex nature of environmental adaptation and suggests that the inherent chilling requirement of seedlings should not be the only consideration. Although the number of budbreak on intact shoots does not distinguish between paradormancy and ecodormancy factors as a response to chilling, it does quantify the phenotypic reaction of individual seedlings to climatic stimuli after a sufficient period following commencement of budbreak.

This study suggests that the variation in prolonged dormancy symptoms is measurable and can be further explored for breeding purposes. High genetic variation within crosses is directly related to variation generated by crossing heterozygous parents. Since the families involved different cultivars in each case and all seedlings were grown in the same environment this must lead to the con- 
clusion that the variation is at least partially genetic and therefore amenable to change by selection. Although the experimental design was not appropriate for estimating heritability, we nevertheless feel confident that a oneshot mass selection among seedlings within crosses based on our measurements of prolonged dormancy symptoms should result in genetic response and improved adaptation to local conditions. It remains to devise some procedure for early selection, perhaps by defining independent culling levels or an appropriate selection index using time and number of budbreak as predictive selection tool.

\section{Literature Cited}

Bell, R.L. and J. Janick. 1990. Quantitative genetic analysis of fruit quality in pear. J. Amer. Soc. Hort. Sci. 115:829-834.

Bradshaw, H.D., Jr., and R.F. Stettler. 1995. Molecular genetics of growth and development in poplars. IV. Mapping QTLs with large effects on growth, form, and phenology traits in a forest tree. Genetics 139:963-973.

Brooks, R.M. and H.P. Olmo. 1972. Register of new fruit and nut varieties. Univ. of California Press, Berkeley.

Brown, A.G. 1960. The inheritance of shape, size and season of ripening in families of the cultivated apple. Euphytica 9:327-337.

Cook, N.C. and G. Jacobs. 2000. Progression of apple (Malus $\times$ domestica Borkh.) bud dormancy in two mild winter climates. J. Hort. Sci. and Biotechnol. 75:233-236.

Cook, N.C., E. Rabe, and G. Jacobs. 1999. Early expression of apical control regulates length and crotch angle of sylleptic shoots in peach and nectarine. HortScience 34:604-606.

Cook, N.C., E. Rabe, J. Keulemans, and G. Jacobs 1998. The expression of acrotony in deciduous fruit trees: A study of the apple rootstock M.9. J. Amer. Soc. Hort. Sci. 123:30-34.

Costes, E. and Y. Guédon. 1997. Modeling the sylleptic branching on one-year-old trunks of apple cultivars. J. Amer. Soc. Hort. Sci. 122:5362.

Dicenta, F., J.E. Garcia, and E.A. Carbonell. 1993 Heritability of fruit characters in almond. J. Hort. Sci. 68:121-126.

Falconer, D.S. and T.F.C. Mackay, 1996. Introduction to quantitative genetics. 4th ed. Longman, New York.

Faust, M., D. Liu, S.Y. Wang, and G.W. Stutte 1995. Involvement of apical dominance in winter dormancy of apple buds. Acta Hort. 395:4756.

Hansche, P.E., V. Beres, and R.M. Brooks. 1966. Heritability and genetic correlation in the sweet cherry. Proc. Amer. Soc. Hort. Sci. 88:173-183.

Hansche, P.E., V. Beres, and H.I. Forde. 1972. Estimates of quantitative genetic properties of walnut and their implications for cultivar improvement. J. Amer. Soc. Hort. Sci. 97:279-285.

Hauagge, R. and J.N. Cummins. 1991a. Phenotypic variation of length of bud dormancy in apple cultivars and related Malus species. J. Amer. Soc. Hort. Sci. 116:100-106.

Hauagge, R. and J.N. Cummins. 1991b. Relationships among indices for the end of bud dormancy in apple cultivars and related Malus species under cold winter conditions. J. Amer. Soc. Hort. Sci. 116:95-99.

Hauagge, R. and J.N. Cummins. 1991c. Genetics of length of dormancy period in Malus vegetative buds. J. Amer. Soc. Hort. Sci. 116:121-126.

Jacobs, G., P.J. Watermeyer, and D.K. Strydom. 1981. Aspects of winter rest of apple trees. Crop Production 10:103-104.

Janick, J., J.N. Cummins, S.K. Brown, and M. Hemmat. 1996. Apples, p. 1-77. In: J. Janick and J.N. Moore (eds.). Fruit breeding. Wiley, New York.

Kempthorne, O. 1957. An introduction to genetic statistics. Wiley, New York.

Khan, A.A. 1997. Quantification of plant dormancy: Introduction to the workshop. HortScience 32:608-614.

Lang, G.A., J.D. Early, N.J. Arroyave, R.L. Darnell, G.C. Martin, and G.W. Stutte. 1985. Dormancy: Toward a reduced, universal terminology. HortScience 20:809-812.
Linsley-Noakes, G.C., P. Allan, and G. Matthee. 1994. Modification of rest completion prediction models for improved accuracy in South African stone fruit orchards. J. S. Afr. Soc. Hort. Sci. 4:13-15.

Martinez, J.J., A.A. Gardea, S. Sagnelli, and J. Olivas. 1999. Sweet cherry adaptation to mild winters. Fruit Var. J. 53:181-183.

Mauget, J.C. and R. Rageau. 1988. Bud dormancy and adaptation of apple tree to mild winter climates. Acta Hort. 232:101-107.

Powell, L.E. 1986. The chilling requirement in apple and its role in regulating time of flowering in spring in cold-winter climates. Acta Hort. 179:129-139.

Richardson, E.A., S.D. Seeley, and D.R. Walker. 1974. A model for estimating the completion of rest for 'Redhaven' and 'Elberta' peach trees. HortScience 9:331-332.

SAS Institute, Inc. 1996. The SAS System. Release 6.12. SAS Institute, Cary, N.C.

Shaltout, A.D. and C.R. Unrath. 1983. Rest completion prediction model for 'Starkrimson Delicious' apples. J. Amer. Soc. Hort. Sci. 108:957961.

Shapiro, S.S. and M.B. Wilk. 1965. An analysis of variance test for normality (complete samples). Biometrika 52:591-611.

Snedecor, G.W. and W.G. Cochran. 1991. Statistical methods. Eighth Edition. Iowa State Univ. Press, Ames.

Sorensen, F.C. 1983. Relationship between logarithms of chilling period and germination or bud flush rate is linear for many tree species. For. Sci. 29:237-240

Tancred, S.J., A.G. Zeppa, M. Cooper, and J.K. Stringer. 1995. Heritability and patterns of the ripening date of apples. HortScience 30:325328

Weinberger, J.H. 1944. Characteristics of the family of certain peach varieties. Proc. Amer. Soc. Hort. Sci. 45:233-238.

Wilson, D., R.P. Jones, and J. Reeves. 1975. Selection for prolonged winter dormancy as a possible aid to improving yield stability in European plum (Prunus domestica L.). Euphytica 24:815-819. 